\title{
Erratum zu: Organisation und Zivilgesellschaft
}

\author{
Andreas Schröer, Nicolas Engel, Claudia Fahrenwald, \\ Michael Göhlich, Christian Schröder und Susanne Maria Weber
}

\section{Erratum zu:}

\section{A. Schröer et al. (Hsrg.), Organisation und Zivilgesellschaft, Organisation und Pädagogik 24, https://doi.org/10.1007/978-3-658-18005-8}

Die Originalversion des Buchs wurde revidiert. Die Angaben der Herausgeberin und Mitautorin von zwei Kapiteln Claudia Fahrenwald wurden wie folgt korrigiert:

Claudia Fahrenwald

Pädagogische Hochschule Oberösterreich

Linz, Österreich 